\title{
Quercetin But Not Quercitrin Ameliorates Tumor Necrosis Factor-Alpha- Induced Insulin Resistance in C2C12 Skeletal Muscle Cells
}

\author{
Xiaoqian Dai, Ye Ding, Zhaofeng Zhang, Xiaxia Cai, Lei Bao, and Yong Li* \\ Department of Nutrition and Food Hygiene, School of Public Health, Peking University Health Science Center; No. \\ 38 Xueyuan Road, Haidian District, Beijing 100191, China. \\ Received October 26, 2012; accepted February 17, 2013; advance publication released online February 23, 2013
}

\begin{abstract}
Skeletal muscle is a major site for glucose metabolism and its injury by cytokines can induce insulin resistance leading to type 2 diabetes. It has been suggested that quercetin may act as anti-diabetic agent, however, the effects of quercetin on insulin resistance in skeletal muscle remain unknown. We aimed to investigate the role of quercetin and its glycoside, quercitrin in tumor necrosis factor-alpha (TNF- $\alpha$ ) induced C2C12 skeletal muscle cell impairment. Quercetin, but not quercitrin moderately attenuated the effects of TNF- $\alpha$ and enhanced the basal and insulin stimulated uptake of glucose in a dose-dependent manner via the activation of the protein kinase B (Akt) and AMP-activated protein kinase (AMPK) pathways. Furthermore, the underlying mechanism also involved the suppression of nuclear factor- $\kappa \mathrm{B}(\mathrm{NF}-\boldsymbol{\kappa} \mathrm{B})$ signaling and the nitric oxide (NO)/inducible nitric oxide synthase (iNOS) system, downstream of AMPK transduction. In summary, quercetin exhibited its effect of improving glucose uptake and insulin sensitivity in skeletal muscle cells via the two independent signaling pathways of Akt and AMPK, and can be developed as a potential anti-diabetic agent.
\end{abstract}

Key words skeletal muscle cell; insulin resistance; quercetin; inflammation; AMP-activated protein kinase

Type 2 diabetes is characterized by low-grade systemic inflammation, ${ }^{1)}$ and elevated levels of circulating proinflammatory mediators may lead to the process of insulin resistance, a critical issue for understanding the mechanisms that contribute to type 2 diabetes. ${ }^{2,3)}$ Cytokines like tumor necrosis factor-alpha (TNF- $\alpha$ ) directly bind to their receptor(s) on muscle cells or hepatocytes, interfere with intracellular insulin signaling by converging on common signaling routes like the nuclear factor- $\kappa \mathrm{B}(\mathrm{NF}-\kappa \mathrm{B})$ pathway, and eventually dampen the cellular response to insulin. ${ }^{3-5)}$

Skeletal muscle is recognized as the major tissue for glucose metabolism, taking up nearly three quarters of insulin stimulated glucose uptake in the entire body. ${ }^{6}$. There are at least two major mechanisms for the uptake of glucose by glucose transporter 4 (Glut4) in skeletal muscle: one is an insulin-dependent phosphoinositide 3 (PI3) kinase and protein kinase $\mathrm{B}(\mathrm{Akt})$ pathway, while the other is an AMP-activated protein kinase (AMPK) signaling pathway stimulated by metabolic stress. ${ }^{7,8)}$ The serine/threonine kinase Akt, also known as protein kinase $\mathrm{B}(\mathrm{PKB})$ is a pivotal node in cell signaling downstream of growth factors, cytokines and other stimuli. ${ }^{9)}$ Cytokines may also affect insulin independent pathways regulating glucose disposal such as inhibiting the activation of AMPK ${ }^{10)}$ AMPK is a fuel-sensing enzyme, the phosphorylation of which regulates glucose uptake. ${ }^{11)}$ However, its role in skeletal muscle remains unclear. ${ }^{12,13)}$

Dietary compounds with anti-inflammatory properties that affect insulin sensitivity may be promising candidates for manipulating skeletal muscle insulin resistance for their low side effects and readily available natural sources. Quercetin $\left(3,5,7,3^{\prime}, 4^{\prime}\right.$-pentahydroxyflavone) is found in various plants or plant-related sources, however, vegetables and fruits almost exclusively contain quercetin glycoside rather than quercetin aglycone. ${ }^{14)}$ Studies have revealed a role for quercetin in reducing pancreatic oxidative stress during diabetes. ${ }^{15)}$ Querce-

The authors declare no conflict of interest. tin was also shown to attenuate inflammation via inhibiting the $\mathrm{NF}-\kappa \mathrm{B}$ pathway and nitric oxide (NO)/inducible nitric oxide synthase (iNOS) system, ${ }^{16-18)}$ which suggests that it may potentially be an alternative treatment for insulin resistance in diabetes. However, there are few studies on the effects of quercetin on insulin resistance in skeletal muscle, and it has been suggested that quercetin promotes basal glucose uptake in $\mathrm{C} 2 \mathrm{C} 12$ cells via AMPK activation as the mechanism behind the insulin-sensitizing effects. ${ }^{19)}$ In addition, the majority of studies focus on the aglycone form (quercetin), and the glycoside form (quercitrin) attracts little attention due to the lack of commercial standards. ${ }^{20)}$

In this study, we aimed to investigate the effects of the aglycone (quercetin) and rhamnose glucoside (quercitrin) in TNF- $\alpha$-induced insulin resistance in $\mathrm{C} 2 \mathrm{C} 12$ murine skeletal myoblasts. As several studies on quercetin in diabetes have focused on the oxidative injury of tissues like pancreas or liver, ${ }^{21,22)}$ this study investigated the role of quercetin in insulin sensitivity from a relatively novel perspective. Our results demonstrate that quercetin rather than quercitrin may be a potential therapeutic agent for insulin resistance in diabetes.

\section{MATERIALS AND METHODS}

Reagents Dulbecco's modified Eagle's medium (DMEM) and fetal bovine serum (FBS) were purchased from GIBCO (Auckland, NZ, U.S.A.). Quercetin and quercitrin were purchased from Sigma-Aldrich (St. Louis, MO, U.S.A.). PhosphoAMPK (Thr172), Phospho-Akt (Ser473), AMPK, Akt, iNOS, NF- $\kappa \mathrm{B}$ (p65 subunit), $\beta$-actin antibodies, secondary horseradish peroxidase linked antibodies and enhanced chemiluminescence (ECL) were purchased from Cell Signaling Technology (New England Biolabs, Beverly, MA, U.S.A.). TNF- $\alpha$ was obtained from Peprotech (Rocky Hill, U.S.A.). Insulin and compound $\mathrm{C}$ were purchased from Calbiochem (San Diego, CA, U.S.A.). Quercetin and quercitrin were dissolved in $0.1 \%$ dimethyl sulfoxide (DMSO). 
Cell Culture $\mathrm{C} 2 \mathrm{C} 12$ cells were purchased from American Type Culture Collection (Manassas, VA, U.S.A.), and were cultured in DMEM containing 10\% FBS, $100 \mathrm{U} / \mathrm{mL}$ penicillin, $100 \mu \mathrm{g} / \mathrm{mL}$ streptomycin, $2 \mathrm{mmol} / \mathrm{L}$ within a humidified atmosphere $\left(5 \% \mathrm{CO}_{2}, 37^{\circ} \mathrm{C}\right)$ until $80 \%$ confluence. Then the medium was replaced with differentiation medium containing $2 \%$ horse serum until cells were differentiated to mature myotubes.

Viability of C2C12 Cells Cells were pretreated with quercetin or quercitrin $(0,5,10,20 \mu \mathrm{M})$ for $2 \mathrm{~h}$, then co-incubated with TNF- $\alpha(10 \mathrm{ng} / \mathrm{mL})$ and quercetin or quercitrin for $24 \mathrm{~h}$. Cells were washed twice and incubated with $100 \mathrm{mg} / \mathrm{mL}$ 3-(4,5-dimethylthiazol-2-y1)-2,5-diphenyltetrazolium bromide (MTT) for $4 \mathrm{~h}$ in the dark $\left(5 \% \mathrm{CO}_{2}, 37^{\circ} \mathrm{C}\right)$, then the formazan in the cells was dissolved in $200 \mu \mathrm{L}$ DMSO. The absorbance was measured at $570 \mathrm{~nm}$ on a microplate reader. All experiments were performed in triplicate.

Glucose Uptake Assay Cells underwent $2 \mathrm{~h}$ of quercetin or quercitrin $(0,5,10,20 \mu \mathrm{M})$ treatment prior to TNF- $\alpha(10 \mathrm{ng} /$ $\mathrm{mL}$ ) incubation, and after co-incubated of TNF- $\alpha$ and quercetin or quercitrin for $24 \mathrm{~h}$. Glucose transport was measured as described. $^{23)}$ After serum starvation for $12 \mathrm{~h}$ and stimulation by $100 \mathrm{~nm}$ insulin (or not) for $30 \mathrm{~min}$, cells were incubated with medium containing $\left[{ }^{3} \mathrm{H}\right]-2$-deoxyglucose (DG) $(25 \mathrm{~mm}$; $10 \mathrm{mCi} / \mathrm{mL}$ ) for $10 \mathrm{~min}$ at $37^{\circ} \mathrm{C}$. The reaction was terminated by ice-cold phosphate buffered saline and the radioactivity measured by scintillation counting. Cytochalasin B (10 mm) was used for measurement of nonspecific background which was subtracted from the total uptake. The results were normalized to protein content.

NO Metabolite (Nitrite) Measurement After pretreatment with quercetin or quercitrin $(0,5,10,20 \mu \mathrm{M})$ for $2 \mathrm{~h}$, cells were co-incubated with TNF- $\alpha(10 \mathrm{ng} / \mathrm{mL})$ and quercetin or quercitrin $(0,5,10,20 \mu \mathrm{M})$ for $24 \mathrm{~h}$, and the supernatant was collected for NO determination using Nitric Oxide Colorimetric Assay Kit, Catalog K262-200 (BioVision, Inc., U.S.A.). NO is rapidly oxidized to nitrite and nitrate which are used to quantitate NO production. The total nitrate/nitrite are measured in a simple two-step process. The first step converts nitrate to nitrite utilizing nitrate reductase. The second step uses Griess Reagents to convert nitrite to a deep purple azo compound, which absorbs light at $540 \mathrm{~nm}$. The concentrations of nitrite were then determined using a linear standard curve obtained from serial dilutions of sodium nitrite.

Immunoblot Analysis Cells were pretreated with quercetin $(20 \mu \mathrm{M})$ for $2 \mathrm{~h}$, then treated with compound $\mathrm{C}(10 \mu \mathrm{M})$ $30 \mathrm{~min}$ prior to TNF- $\alpha(10 \mathrm{ng} / \mathrm{mL})$ and quercetin co-incubation of $24 \mathrm{~h}$ and then with insulin simulation for $30 \mathrm{~min}$. Protein was extracted in radio immunoprecipitation assay lysis buffer containing $1 \%$ phenylmethylsulfonyl fluoride and $1 \%$ Protease Inhibitor Cocktail, and the protein samples $(40 \mu \mathrm{g})$ were mixed with $5 \mathrm{X}$ sample loading buffer, and separated via sodium dodecyl sulfate polyacrylamide gel electrophoresis. Proteins were transferred to polyvinylidene difluoride membranes, which were then blocked with $5 \%$ skim milk for $1 \mathrm{~h}$ at room temperature and incubated at $4^{\circ} \mathrm{C}$ overnight with primary antibodies. The membranes were then incubated with HRPconjugated second anti-immunoglobulin $\mathrm{G}$ for $2 \mathrm{~h}$ and visualized by ECL. The integrated optical density (OPTDI) of each band was normalized to an internal control, $\beta$-actin band for comparison.

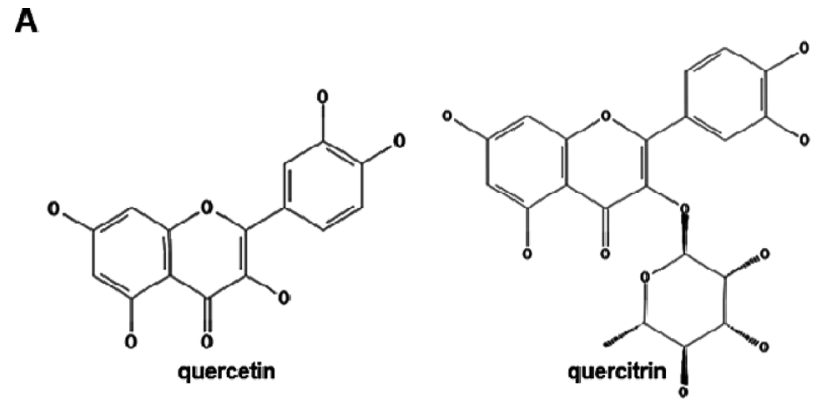

B

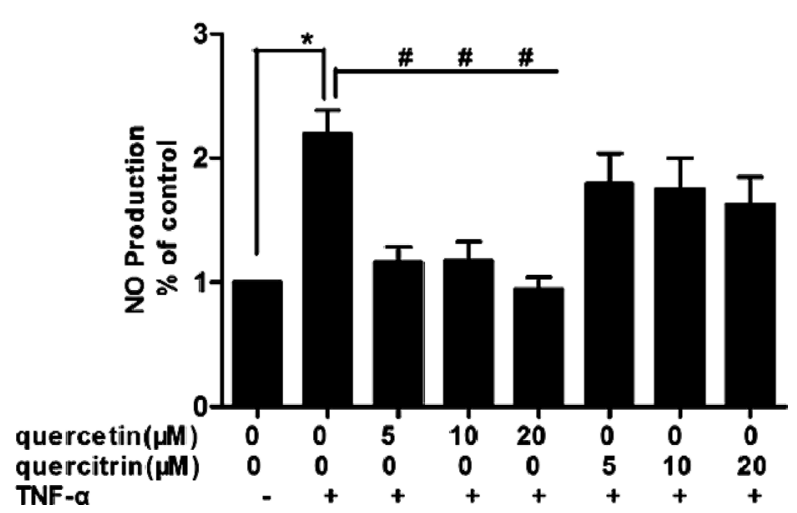

Fig. 1. The Chemical Structure of Quercetin/Quercitrin and Only Quercetin Inhibited NO Production

(A) The chemical structure of quercetin and quercitrin. (B) After pretreatment with quercetin or quercitrin $(0,5,10,20 \mu \mathrm{M})$ for $2 \mathrm{~h}$, cells were co-incubated with TNF- $\alpha(10 \mathrm{ng} / \mathrm{mL})$ and quercetin or quercitrin $(0,5,10,20 \mu \mathrm{M})$ for $24 \mathrm{~h}$, NO concentration was determined from cell-free medium by Griess assay. $* p<0.05$ vs. untreated control; ${ }^{\#} p<0.05$ vs. cytokine alone.

Data Analysis All the data were presented as meant S.E.M. of three independent experiments, and compared via one-way ANOVA for differences between groups, or with the Bonferroni-Dunnett T3 test for multiple comparisons. Statistical analyses were performed using SPSS 17.0 software, and a value of $p<0.05$ was considered statistically significant.

\section{RESULTS}

Quercetin or Quercitrin Had No Effect on C2C12 Myotube Viability, and Only Quercetin Suppressed NO Production Stimulated by TNF- $\alpha$ Indicated doses of quercetin or quercitrin did not affect cell viability compared to the untreated group (supplementary Fig. 1A). TNF- $\alpha$ (10 ng/ $\mathrm{mL}$ ) significantly decreased $\mathrm{C} 2 \mathrm{C} 12$ viability compared to the untreated group, however, neither quercetin nor quercitrin rescued the decreased viability caused by the cytokine (supplementary Fig. 1B).

TNF- $\alpha(10 \mathrm{ng} / \mathrm{mL})$ significantly promoted NO production in $\mathrm{C} 2 \mathrm{C} 12$ myotubes. Only quercetin $(5,10,20 \mu \mathrm{M})$ inhibited this increased production significantly, and quercetin $(20 \mu \mathrm{M})$ had the strongest effect. In comparison, the quercitrin group showed no suppression effect (Fig. 1B).

Quercetin But Not Quercitrin Enhanced Both Basal and Insulin Stimulated Glucose Uptake, and Countered the Effects of TNF- $\alpha$ In our pilot experiment (data not shown), we have tried gradient increased treatment time to decide the most effective action time, and finally, we chose $2 \mathrm{~h}$ pretreat- 
A

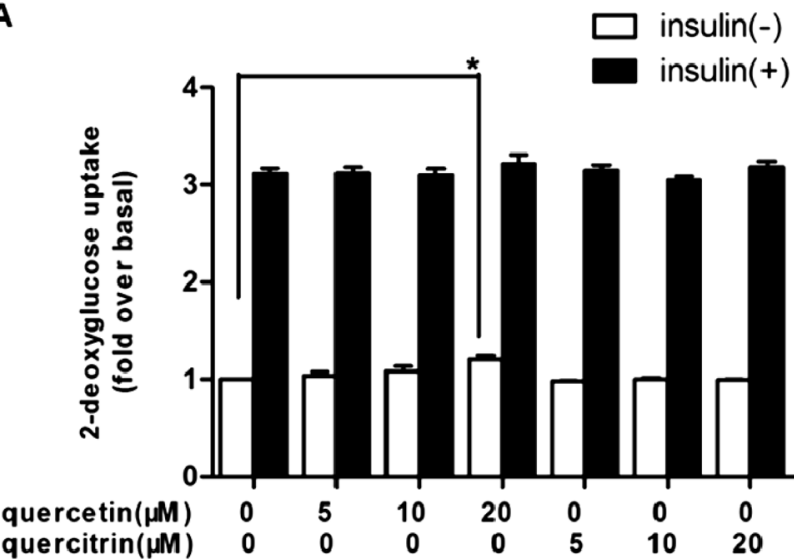

B

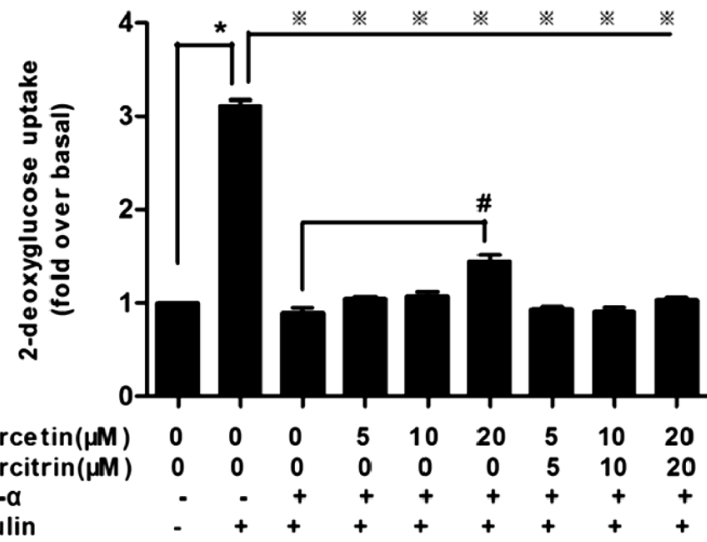

Fig. 2. Quercetin Exerted a Weak Insulin-Like Effect on Normal Cells and Moderately Enhanced Insulin Stimulated Glucose Uptake in Cytokine-Treated Cells While Quercitrin Had No Influence

(A) Cells were incubated with quercetin or quercitrin $(0,5,10,20 \mu \mathrm{M})$, and treated with or without insulin $(100 \mathrm{~nm})$ for $30 \mathrm{~min}$ before glucose uptake assay. (B) Cells underwent $2 \mathrm{~h}$ of quercetin or quercitrin $(0,5,10,20 \mu \mathrm{M})$ treatment prio to TNF- $\alpha(10 \mathrm{ng} / \mathrm{mL})$ incubation, and after co-incubated of TNF- $\alpha$ and quercetin or quercitrin for $24 \mathrm{~h}$, cells were stimulated by insulin ( $100 \mathrm{~nm}$ ) for $30 \mathrm{~min}$ before glucose uptake assay. ${ }^{*} p<0.05$ vs. untreated control; ${ }^{*} p<0.05$ vs. cytokine alone * $p<0.05 v s$. insulin alone.

ment plus $24 \mathrm{~h}$ treatment of quercetin as our final used treatment time.

High dose of quercetin $(20 \mu \mathrm{M})$ moderately promoted glucose uptake in $\mathrm{C} 2 \mathrm{C} 12$ myotubes in the absence of insulin stimulation; but had no significant effects on insulin-treated cells. The quercitrin group showed no differences compared to the untreated group (Fig. 2A).

Insulin remarkably facilitated glucose uptake in $\mathrm{C} 2 \mathrm{C} 12$ myotubes, however, this bioactivity was inhibited by TNF- $\alpha$ $(10 \mathrm{ng} / \mathrm{mL})$. Insulin produced a 3 -fold increase in cellular glucose uptake compared to the basal condition, and the cytokine blunted this stimulation and decreased glucose uptake to basal levels. Quercetin moderately ameliorated cytokine-induced inhibition in a dose-dependent manner, and the highest concentration $(20 \mu \mathrm{M})$ raised glucose uptake with the most significant effect, but the effect is not obvious. However, no significant differences were observed in the quercitrin group compared to the cytokine group (Fig. 2B).

Quercetin Promoted AMPK and Akt Activation While Suppressing the iNOS and NF- $\kappa$ B Pathways in TNF$\alpha$-Treated C2C12 Myotubes As only quercetin, not its glycoside quercitrin, showed NO suppression and glucose uptake enhancement in TNF- $\alpha(10 \mathrm{ng} / \mathrm{mL})$ treated cells, we used only quercetin for the following experiments.

Insulin enhanced both the total AMPK and phospho-AMPK (Thr172) protein levels compared to the untreated group, however, the overall extent of phosphorylation of AMPK was similar between the untreated and insulin group. AMPK phosphorylation was significantly inhibited in the cytokine group compared to either the untreated or insulin groups, while quercetin enhanced AMPK phosphorylation in a dose-dependent manner. The highest concentrations of quercetin (10, $20 \mu \mathrm{M})$ significantly reversed cytokine inhibition of AMPK phophorylation (Fig. 3A).

In addition, insulin promoted Akt phosphorylation compared to the untreated group, while TNF- $\alpha(10 \mathrm{ng} / \mathrm{mL})$ disrupted this effect. However, Akt phosphorylation was significantly higher in quercetin groups $(5,20 \mu \mathrm{M})$ than in the cytokine group (Fig. 3B). iNOS (Fig. 3C) and NF- $\kappa$ B (Fig. 3D) expression was higher in the cytokine group than in the insulin or untreated group, and this up-regulation was suppressed by quercetin $(5,10,20 \mu \mathrm{M})$ in a dose dependent manner.

Quercetin Activated Akt Independent of the AMPK Pathway and Inhibited iNOS and NF- $\kappa$ B via an AMPK Dependent Pathway in TNF- $\alpha$-Treated C2C12 Myotubes In order to investigate the interaction of AMPK, Akt, iNOS and NF- $\kappa \mathrm{B}$ pathways in the mechanism underlying quercetin's effects on TNF- $\alpha$ treated $\mathrm{C} 2 \mathrm{C} 12$ myotubes, we chose the most effective dose of quercetin $(20 \mu \mathrm{M})$ for further study.

The addition of compound $\mathrm{C}$, an AMPK specific inhibitor, did not alter Akt expression compared to quercetin alone (Fig. 4A). However, when cells were treated with compound $\mathrm{C}$ and then quercetin, the inhibition of $\mathrm{NF}-\kappa \mathrm{B}$ expression was abolished (Fig. 4B). At the same time, blockage of AMPK abolished the suppression of iNOS brought about by quercetin (Fig. 4C). Besides, it seems insulin did not influence the mechanism of quercetin as there were no differences for Akt, iNOS, and NF- $\kappa \mathrm{B}$ expression between control group of untreated and insulin alone (supplementary data, Fig. 6, data not shown). In addition, quercetin could not alter the studied proteins in $\mathrm{C} 2 \mathrm{C} 12$ cells under normal culture condition (supplementary data, Fig. 6, data not shown).

\section{DISCUSSION}

Skeletal muscle is a major site for the regulation of energy balance and glucose uptake, and is considered an important target for type 2 diabetes. ${ }^{24,25)}$ Several studies have shown that a dietary component directed at inflammatory pathways may be an attractive alternative for preventing or ameliorating skeletal insulin resistance. ${ }^{5)}$ Quercetin is beneficial in a variety of pathological processes including diabetes, ${ }^{26)}$ however, there are few reports on its role in glucose uptake in skeletal muscle. To our knowledge, this is the first study to examine the impact of quercetin on muscle cells in an insulin-resistant state. We examined the effects of quercetin and its glycoside quercitrin on glucose uptake in $\mathrm{C} 2 \mathrm{C} 12$ myotubes, and investigated the underlying mechanisms involved.

Our results showed that quercetin moderately increased basal glucose uptake without insulin stimulation, which indicated its effects on metabolism in skeletal muscle cells to some extent. And this is partially in accordance with the results from Eid et al. that quercetin and quercin glycosides 
A
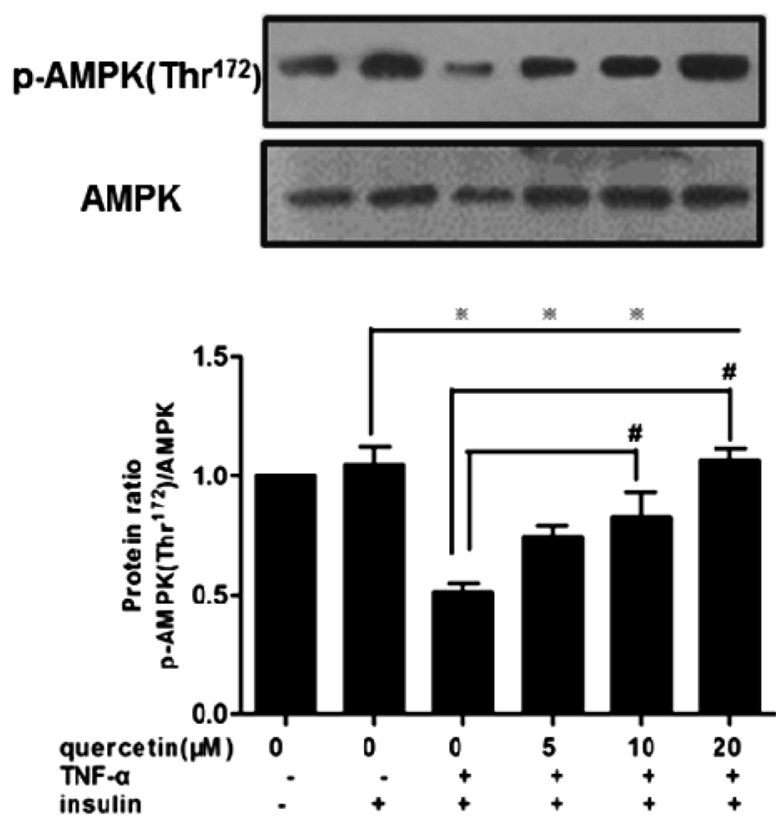

B

p-Akt (Ser $\left.{ }^{473}\right)$

Akt
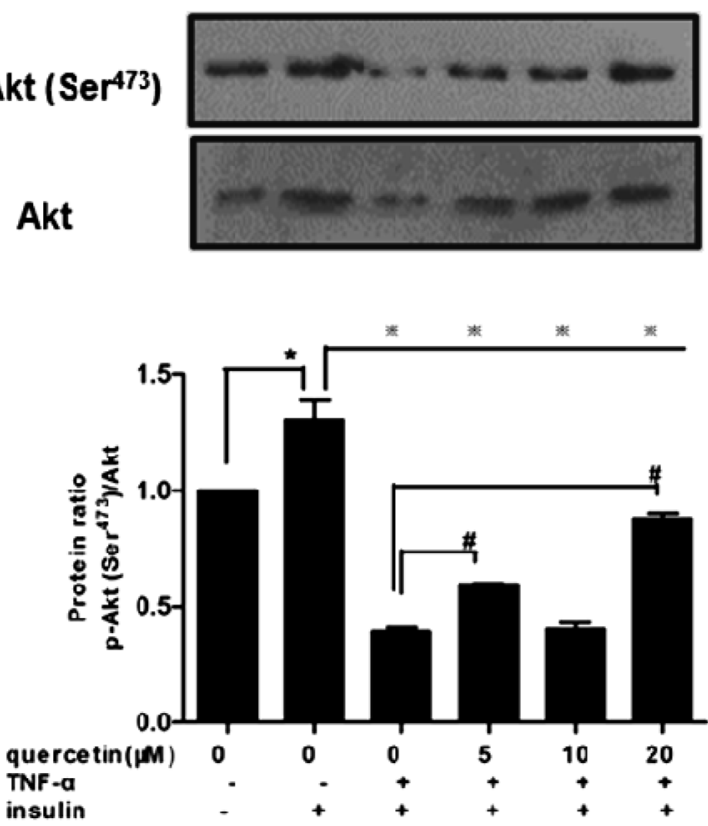

C
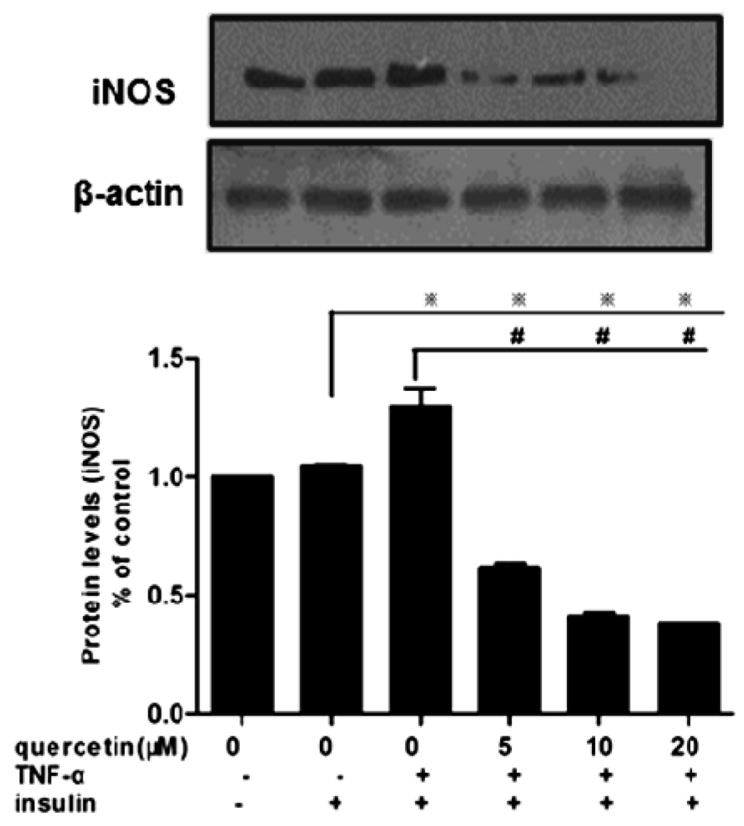

D

NF-KB

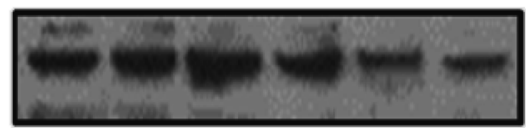

$\beta$-actin
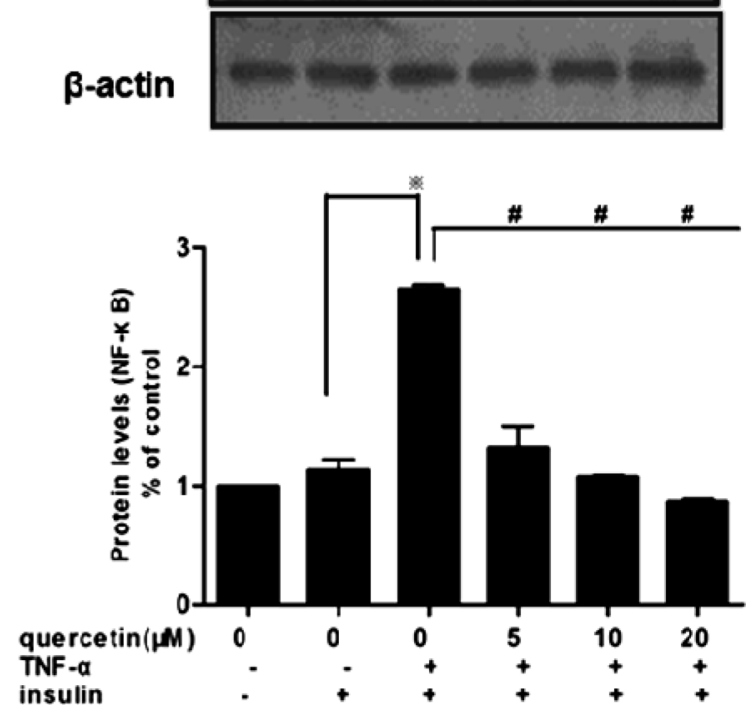

Fig. 3. Quercetin Promoted AMPK and Akt Activation, and Inhibited iNOS and NF- $\kappa$ B Expression in Cytokine-Treated C2C12 Myotubes

Cells were treated with quercetin $(0,5,10,20 \mu \mathrm{M})$ for $2 \mathrm{~h}$ prior to incubation with TNF- $\alpha(10 \mathrm{ng} / \mathrm{mL})$, and after co-incubated with TNF- $\alpha$ and quercetin or quercitrin for $24 \mathrm{~h}$, cells underwent an insulin stimulation for $30 \mathrm{~min}$ before protein extraction. (A) Quercetin promoted AMPK activation. (B) Quercetin enhanced Akt activation. (C) Quercetin inhibited iNOS expression. (D) Quercetin suppressed NF- $\kappa$ B expression. ${ }^{*} p<0.05 v s$. untreated control; ${ }^{*} p<0.05 v s$. cytokine alone; $* p<0.05 v s$. insulin alone.

stimulated AMPK and enhanced basal glucose uptake in $\mathrm{C} 2 \mathrm{C} 12$ myotubes (by about $37 \%)^{19)}$ But the enhancement effect by quercetin in our work are weaker (by about $20 \%$, data not shown), it may results from the dose we used $(5,10$, $20 \mu \mathrm{M})$ is lower than Eid et al. $(100 \mu \mathrm{M})$. As the activation of muscle AMPK by exogenous compounds recruits GLUT4 and augments the rate of glucose transport independent of insulin, ${ }^{27)}$ we suppose that quercetin may also stimulate GLUT4 to promote glucose uptake in $\mathrm{C} 2 \mathrm{C} 12$ myotubes, and we have verified it in other works (data not shown). Also, previous studies have demonstrated that quercetin could increase GLUT4 in both ob/ob mice and skeletal muscle myotubes. ${ }^{28,29)}$ And, we noticed that some study found that quercetin inhibited glucose uptake in normal adipocytes ${ }^{30,31)}$ or acutely impaired glucose metabolism in hamsters, ${ }^{32}$ ) however, as quercetin may be of little value in normalglycemic animals ${ }^{33)}$ and the ways of glucose utilization remains some difference between skeletal muscle and adipose tissue, the weight of such negative results from nondiabetic animal or cells seems weakened. In addition, we did not find that the glycoside quercitrin enhanced glucose uptake in these cells (chemical structures shown in Fig. 1A). We presume that the rhamnose sugar moiety at C3 might re- 
A
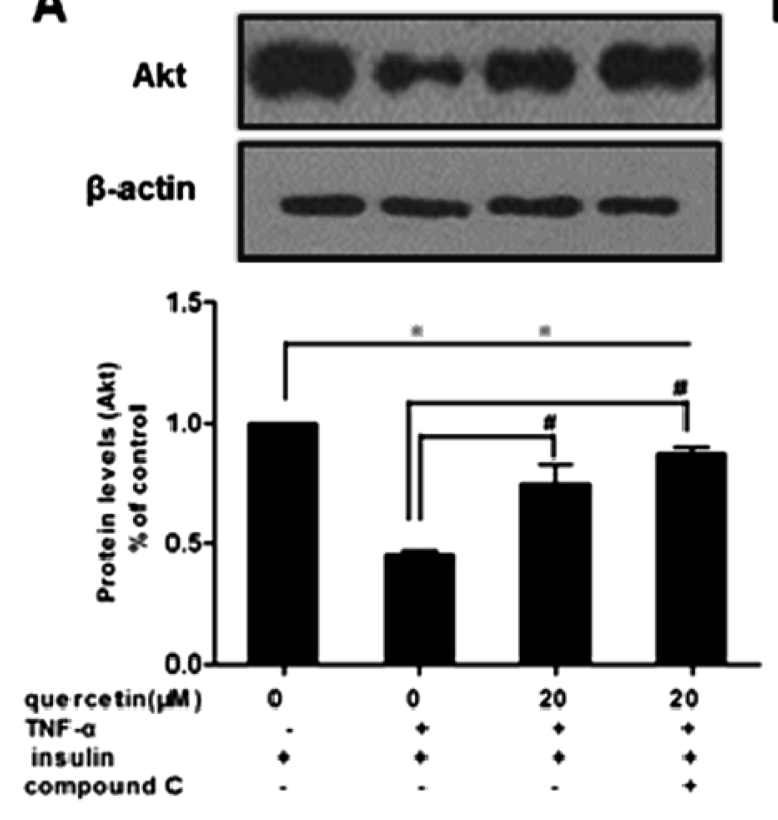

B

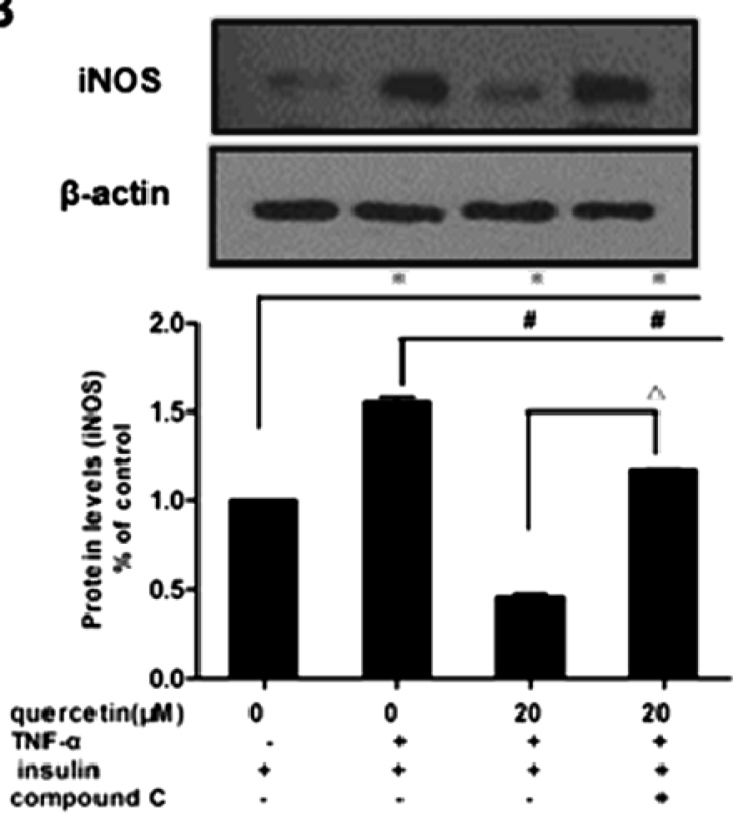

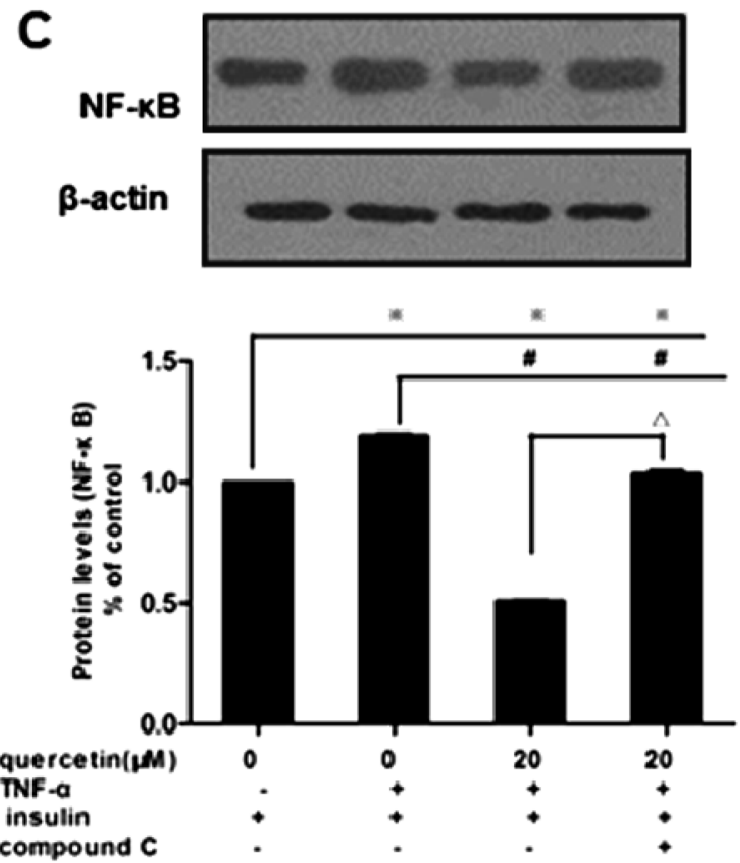

Fig. 4. Quercetin Activated Akt Independent of the AMPK Pathway, and Suppressed iNOS and NF- $\kappa$ B Expression in an AMPK Dependent Manner in TNF- $\alpha$-Treated C2C12 Myotubes

Cells were pretreated with quercetin $(20 \mu \mathrm{M})$ for $2 \mathrm{~h}$, then treated with compound $\mathrm{C}(10 \mu \mathrm{M}) 30 \mathrm{~min}$ prior to TNF- $\alpha(10 \mathrm{ng} / \mathrm{mL})$ and quercetin co-incubation of $24 \mathrm{~h}$ and then with insulin simulation for $30 \mathrm{~min}$. (A) Quercetin enhanced Akt expression independent of AMPK. (B) Quercetin suppressed iNOS expression dependent of AMPK (C) Quercetin inhibited NF- $\kappa$ B expression partially via AMPK. ${ }^{*} p<0.05 v s$. cytokine alone; $* p<0.05 v s$. insulin alone, $\triangle p<0.05 v s$. compound C group.

duce the lipophilicity of quercitrin, thus influencing its ability to permeate the muscle cells.

Importantly, we found that quercetin mitigated TNF- $\alpha$ induced insulin resistance in $\mathrm{C} 2 \mathrm{C} 12$ myotubes, however, the effect is moderate and weaker than the result from Anhe et al. where quercetin have a more marked enhancement effect toward the impaired insulin stimulated glucose uptake by TNF- $\alpha$ in L6 myotubes. ${ }^{29)}$ We suppose that $\mathrm{C} 2 \mathrm{C} 12$ may be less sensitive than L6 myotubes when stimulated by quercetin under insulin resistance. TNF- $\alpha$ is a proinflammatory cytokine that triggers several signaling cascades, including critical insulin action inhibitors, ${ }^{8,34)}$ and the precise molecular signals underlying TNF- $\alpha$ induced metabolic dysregulation remain obscure. Our study indicated that TNF- $\alpha$ significantly blunted glucose uptake and inhibited insulin sensitivity in $\mathrm{C} 2 \mathrm{C} 12$ myotubes partially via the inhibition of Akt phosphorylation and AMPK signaling, which is consistent with previous studies. $^{4,10)}$ Especially to deserve to be mentioned, as apoptosis derived skeletal muscle atrophy may produce insulin resistance, ${ }^{35)}$ reduced viability of $\mathrm{C} 2 \mathrm{C} 12$ by $\mathrm{TNF}-\alpha$ in our experiment indicated that TNF- $\alpha$ might cause apoptosis in $\mathrm{C} 2 \mathrm{C} 12$, however, it seems that neither quercetin nor quercitrin operated through pathways of cell death as they could not improve the impaired cell viability by TNF- $\alpha$, which needs further 
study. Akt signaling regulates nutrient uptake and metabolism, and one of the most critical physiological function of Akt is to acutely enhance glucose uptake in response to insulin., ${ }^{9,36}$ We found that quercetin reversed the inhibition of insulindependent phosphorylation of Akt caused by TNF- $\alpha$ in $\mathrm{C} 2 \mathrm{C} 12$ myotubes. However, Akt signaling is seldom mentioned as a mechanism underlying the effects of quercetin in diabetes, and Kim et al. found that quercetin, in fact, did not activate Akt in INS-1 cells treated with $\mathrm{H}_{2} \mathrm{O}_{2} \cdot{ }^{37)}$ This discrepancy is likely a result of the different cell types and stimuli used, since Akt operates in a cell-type-specific manner. ${ }^{9)}$ And on the basis of our work and previous studies, ${ }^{19,29)}$ it seems that the stimulation of Akt by quercetin only applies to skeletal muscle cells under the insulin resistance, and is not available for normal muscle cells.

In addition, we found quercetin activated AMPK signaling, another way to modulate glucose uptake in muscle cells. AMPK regulates carbohydrate metabolism, increases the uptake of glucose from the blood to target organs in an insulin-independent way, and is considered a potential target in treating or preventing diabetes. ${ }^{7)}$ Although it has been hypothesized that the activation of AMPK enhances sensitivity to insulin, ${ }^{38)}$ it is still necessary to explore the potential downstream effectors that alter insulin action after AMPK activation. AMPK has been shown to promote the phosphorylation of Akt substrate of $160 \mathrm{kDa}$ (AS160), ${ }^{39)}$ suggesting that these two pathways may converge in the mechanism underlying quercetin's effects on improving insulin stimulated glucose uptake in $\mathrm{C} 2 \mathrm{C} 12$ mytotubes. Our results, however, indicate that the AMPK and Akt pathways transmit their signals independently of each other. Besides, it seems that in our work the increase of Akt and AMPK by quercetin do not match with the weak promotion of glucose uptake by quercetin so homogeneously. As TNF- $\alpha$ would trigger several signaling cascades, we supposed it may also interfere $\mathrm{C} 2 \mathrm{C} 12$ glucose uptake via other ways beside AMPK and Akt, which caused weak enhance effect by quercetin, or the contribution of phosphorylation of AMPK and Akt may be offset by other signals to some extent.

We also show that quercetin suppressed NF- $\kappa$ B expression stimulated by TNF- $\alpha$, and this finding was consistent with previously published results showing that quercetin inhibited $\mathrm{NF}-\kappa \mathrm{B}$ in osteoclast, pulmonary epithelial and mast cells. ${ }^{40-42)}$ However, it has also been reported that dietary quercetin did not reduce NF- $\kappa \mathrm{B}$ expression/activation in the renal cortex of rats, ${ }^{43}$ which suggests that flavonoids may act in an organspecific manner. A more thorough understanding of the effects of dietary quercetin will require further investigation. NF- $\kappa \mathrm{B}$ plays an important role in inflammation-induced insulin resistance: when liberated for translocation into the nucleus, it promotes the expression of numerous target genes whose products lead to insulin resistance. ${ }^{44)}$ Recent data showed that AMPK activation suppressed $\mathrm{NF}-\kappa \mathrm{B}$-induced inflammatory responses in macrophages and the diabetic retina. ${ }^{45,46)}$ In accordance with this data, we found that the inhibition of NF- $\kappa$ B expression by quercetin was negated when the AMPK pathway was blocked by compound C. As NF- $\kappa$ B is a key component of the intracellular inflammatory process and required for iNOS induction by proinflammatory cytokines, ${ }^{44,47)}$ we hypothesized that the inhibition of NF- $\kappa$ B by AMPK activation may also influence the NO/iNOS system. The decreased NO production and iNOS expression we measured verified our hypothesis. iNOS generates NO and its induction in inflammatory conditions can promote the development of insulin resistance. ${ }^{48,49)}$ Quercetin counteracted TNF- $\alpha$-induced iNOS induction, and this effect may be attributed to the activation of the AMPK pathway. Taken together, these findings revealed that the molecular pathway by which quercetin ameliorated insulin resistance in muscle cells appeared to involve multiple steps, including the inhibition of NF- $\kappa \mathrm{B}$ and iNOS, with AMPK activation being the most upstream reaction in the cascade. However, as the change of proteins measured in this work is more remarkable than the promotion of glucose uptake by quercetin in TNF- $\alpha$ induced $\mathrm{C} 2 \mathrm{C} 12$, we reckon that there involve other pathways in the mechanism of quercetin in insulin resistance, which need further investigation.

In conclusion, we found quercetin, but not quercitrin moderately enhanced glucose uptake in muscle cells under both basal, and TNF- $\alpha$-induced insulin resistance conditions. The mechanisms underlying the effects of quercetin in improving insulin sensitivity at least involved two independent signaling pathways of Akt and AMPK, and the inhibition of NF- $\kappa \mathrm{B}$ and iNOS downstream of the AMPK pathway. Quercetin may be a promising alternative for the treatment of insulin resistance in muscle cells.

Acknowledgments This work was part of the project with code H2603/81172652 supported by National Natural Science Foundation of China (NSFC).

\section{REFERENCES}

1) Hotamisligil GS. Inflammation and metabolic disorders. Nature, 444, 860-867 (2006).

2) Wentworth JM, Fourlanos S, Harrison LC. Reappraising the stereotypes of diabetes in the modern diabetogenic environment. Nat. Rev. Endocrinol., 5, 483-489 (2009).

3) Cani PD, Amar J, Iglesias MA, Poggi M, Knauf C, Bastelica D, Neyrinck AM, Fava F, Tuohy KM, Chabo C, Waget A, Delmée E, Cousin B, Sulpice T, Chamontin B, Ferrières J, Tanti JF, Gibson GR, Casteilla L, Delzenne NM, Alessi MC, Burcelin R. Metabolic endotoxemia initiates obesity and insulin resistance. Diabetes, $\mathbf{5 6}$ 1761-1772 (2007).

4) Plomgaard P, Bouzakri K, Krogh-Madsen R, Mittendorfer B, Zierath JR, Pedersen BK. Tumor necrosis factor-alpha induces skeletal muscle insulin resistance in healthy human subjects via inhibition of Akt substrate 160 phosphorylation. Diabetes, 54, 2939-2945 (2005).

5) Hommelberg PP, Langen RC, Schols AM, Mensink RP, Plat J. Inflammatory signaling in skeletal muscle insulin resistance: green signal for nutritional intervention? Curr. Opin. Clin. Nutr. Metab. Care, 13, 647-655 (2010).

6) DeFronzo RA, Jacot E, Jequier E, Maeder E, Wahren J, Felber JP. The effect of insulin on the disposal of intravenous glucose. Results from indirect calorimetry and hepatic and femoral venous catheterization. Diabetes, 30, 1000-1007 (1981).

7) Hwang JT, Kwon DY, Yoon SH. AMP-activated protein kinase: a potential target for the diseases prevention by natural occurring polyphenols. New Biotechnol., 26, 17-22 (2009).

8) Tomás E, Lin YS, Dagher Z, Saha A, Luo Z, Ido Y, Ruderman NB. Hyperglycemia and insulin resistance: possible mechanisms. Ann. N. Y. Acad. Sci., 967, 43-51 (2002).

9) Manning BD, Cantley LC. AKT/PKB signaling: navigating downstream. Cell, 129, 1261-1274 (2007). 
10) Steinberg GR, Michell BJ, van Denderen BJ, Watt MJ, Carey AL, Fam BC, Andrikopoulos S, Proietto J, Görgün CZ, Carling $\mathrm{D}$, Hotamisligil GS, Febbraio MA, Kay TW, Kemp BE. Tumor necrosis factor alpha-induced skeletal muscle insulin resistance involves suppression of AMP-kinase signaling. Cell Metab., 4, 465-474 (2006).

11) Fujii N, Jessen N, Goodyear LJ. AMP-activated protein kinase and the regulation of glucose transport. Am. J. Physiol. Endocrinol. Metab., 291, E867-E877 (2006).

12) Beck Jørgensen S, O’Neill HM, Hewitt K, Kemp BE, Steinberg GR. Reduced AMP-activated protein kinase activity in mouse skeletal muscle does not exacerbate the development of insulin resistance with obesity. Diabetologia, 52, 2395-2404 (2009).

13) Kraegen EW, Bruce C, Hegarty BD, Ye JM, Turner N, Cooney G. AMP-activated protein kinase and muscle insulin resistance. Front. Biosci., 14, 4658-4672 (2009).

14) Miean KH, Mohamed S. Flavonoid (myricetin, quercetin, kaempferol, luteolin, and apigenin) content of edible tropical plants. J. Agric. Food Chem., 49, 3106-3112 (2001).

15) Zunino S. Type 2 diabetes and glycemic response to grapes or grape products. J. Nutr., 139, 1794S-1800S (2009).

16) Granado-Serrano AB, Martín MA, Bravo L, Goya L, Ramos S. Quercetin attenuates TNF-induced inflammation in hepatic cells by inhibiting the NF- $\kappa \mathrm{B}$ pathway. Nutr. Cancer, 64, 588-598 (2012).

17) Zhang ZJ, Cheang LC, Wang MW, Lee SM. Quercetin exerts a neuroprotective effect through inhibition of the iNOS/NO system and pro-inflammation gene expression in PC12 cells and in zebrafish. Int. J. Mol. Med., 27, 195-203 (2011).

18) Liu H, Zhang L, Lu S. Evaluation of antioxidant and immunity activities of quercetin in isoproterenol-treated rats. Molecules, 17, 4281-4291 (2012).

19) Eid HM, Martineau LC, Saleem A, Muhammad A, Vallerand D, Benhaddou-Andaloussi A, Nistor L, Afshar A, Arnason JT, Haddad PS. Stimulation of AMP-activated protein kinase and enhancement of basal glucose uptake in muscle cells by quercetin and quercetin glycosides, active principles of the antidiabetic medicinal plant Vaccinium vitis-idaea. Mol. Nutr. Food Res., 54, 991-1003 (2010).

20) Babujanarthanam R, Kavitha P, Pandian MR. Quercitrin, a bioflavonoid improves glucose homeostasis in streptozotocin-induced diabetic tissues by altering glycolytic and gluconeogenic enzymes. Fundam. Clin. Pharmacol., 24, 357-364 (2010).

21) Cheng FC, Shen SC, Wu JS. Effect of guava (Psidium guajava L.) leaf extract on glucose uptake in rat hepatocytes. J. Food Sci., 74, H132-H138 (2009).

22) Cho JM, Chang SY, Kim DB, Needs PW, Jo YH, Kim MJ. Effects of physiological quercetin metabolites on interleukin-1 $\beta$-induced inducible NOS expression. J. Nutr. Biochem., 23, 1394-1402 (2012).

23) Lee ES, Uhm KO, Lee YM, Han M, Lee M, Park JM, Suh PG, Park SH, Kim HS. CAPE (caffeic acid phenethyl ester) stimulates glucose uptake through AMPK (AMP-activated protein kinase) activation in skeletal muscle cells. Biochem. Biophys. Res. Commun., 361, 854-858 (2007).

24) Sheetz MJ, King GL. Molecular understanding of hyperglycemia's adverse effects for diabetic complications. JAMA, 288, 2579-2588 (2002).

25) Lee SH, Kang SM, Ko SC, Lee DH, Jeon YJ. Octaphlorethol A, a novel phenolic compound isolated from a brown alga, Ishige foliacea, increases glucose transporter 4-mediated glucose uptake in skeletal muscle cells. Biochem. Biophys. Res. Commun., 420, 576-581 (2012)

26) Edwards RL, Lyon T, Litwin SE, Rabovsky A, Symons JD, Jalili T. Quercetin reduces blood pressure in hypertensive subjects. J. Nutr., 137, 2405-2411 (2007).

27) Gruzman A, Babai G, Sasson S. Adenosine monophosphate-activated protein kinase (AMPK) as a new target for antidiabetic drugs: A review on metabolic, pharmacological and chemical considerations. Rev. Diabet. Stud., 6, 13-36 (2009).
28) Shen JZ, Ma LN, Han Y, Liu JX, Yang WQ, Chen L, Liu Y, Hu Y, Jin MW. Pentamethylquercetin generates beneficial effects in monosodium glutamate-induced obese mice and $\mathrm{C} 2 \mathrm{C} 12$ myotubes by activating AMP-activated protein kinase. Diabetologia, 55, 1836-1846 (2012).

29) Anhê GF, Okamoto MM, Kinote A, Sollon C, Lellis-Santos C, Anhê FF, Lima GA, Hirabara SM, Velloso LA, Bordin S, Machado UF. Quercetin decreases inflammatory response and increases insulin action in skeletal muscle of ob/ob mice and in L6 myotubes. Eur. J. Pharmacol., 689, 285-293 (2012).

30) Nomura M, Takahashi T, Nagata N, Tsutsumi K, Kobayashi S, Akiba T, Yokogawa K, Moritani S, Miyamoto K. Inhibitory mechanisms of flavonoids on insulin-stimulated glucose uptake in MC3T3-G2/PA6 adipose cells. Biol. Pharm. Bull., 31, 1403-1409 (2008).

31) Strobel P, Allard C, Perez-Acle T, Calderon R, Aldunate R, Leighton F. Myricetin, quercetin and catechin-gallate inhibit glucose uptake in isolated rat adipocytes. Biochem. J., 386, 471-478 (2005).

32) Koch CE, Ganjam GK, Steger J, Legler K, Stöhr S, Schumacher D, Hoggard N, Heldmaier G, Tups A. The dietary flavonoids naringenin and quercetin acutely impair glucose metabolism in rodents possibly via inhibition of hypothalamic insulin signalling. $\mathrm{Br} . \mathrm{J}$. Nutr., 6, 1040-1051 (2013).

33) Vessal M, Hemmati M, Vasei M. Antidiabetic effects of quercetin in streptozocin-induced diabetic rats. Comp. Biochem. Physiol. C Toxicol. Pharmacol., 135C, 357-364 (2003).

34) Halse R, Pearson SL, McCormack JG, Yeaman SJ, Taylor R. Effects of tumor necrosis factor-alpha on insulin action in cultured human muscle cells. Diabetes, 50, 1102-1109 (2001).

35) Yoon JH, Song P, Jang JH, Kim DK, Choi S, Kim J, Ghim J, Kim D, Park S, Lee H, Kwak D, Yea K, Hwang D, Suh PG, Ryu SH. Proteomic analysis of tumor necrosis factor-alpha (TNF- $\alpha$ )-induced L6 myotube secretome reveals novel TNF- $\alpha$-dependent myokines in diabetic skeletal muscle. J. Proteome Res., 10, 5315-5325 (2011).

36) Bhavsar SK, Föller M, Gu S, Vir S, Shah MB, Bhutani KK, Santani $\mathrm{DD}$, Lang F. Involvement of the PI3K/AKT pathway in the hypoglycemic effects of saponins from Helicteres isora. J. Ethnopharmacol., 126, 386-396 (2009).

37) Kim MK, Jung HS, Yoon CS, Ko JH, Chun HJ, Kim TK, Kwon MJ, Lee SH, Koh KS, Rhee BD, Park JH. EGCG and quercetin protected INS-1 cells in oxidative stress via different mechanisms. Front Biosci (Elite Ed), 2, 810-817 (2010).

38) Fisher JS. Potential role of the AMP-activated protein kinase in regulation of insulin action. Cellscience, 2, 68-81 (2006).

39) Cartee GD, Wojtaszewski JF. Role of Akt substrate of $160 \mathrm{kDa}$ in insulin-stimulated and contraction-stimulated glucose transport. Appl. Physiol. Nutr. Metab., 32, 557-566 (2007).

40) Wattel A, Kamel S, Prouillet C, Petit JP, Lorget F, Offord E, Brazier M. Flavonoid quercetin decreases osteoclastic differentiation induced by RANKL via a mechanism involving NF kappa B and AP-1. J. Cell. Biochem., 92, 285-295 (2004).

41) Weng Z, Zhang B, Asadi S, Sismanopoulos N, Butcher A, Fu X, Katsarou-Katsari A, Antoniou C, Theoharides TC. Quercetin is more effective than cromolyn in blocking human mast cell cytokine release and inhibits contact dermatitis and photosensitivity in humans. PLoS ONE, 7, e33805 (2012).

42) Ying B, Yang T, Song X, Hu X, Fan H, Lu X, Chen L, Cheng D, Wang T, Liu D, Xu D, Wei Y, Wen F. Quercetin inhibits IL-1 beta-induced ICAM-1 expression in pulmonary epithelial cell line A549 through the MAPK pathways. Mol. Biol. Rep., 36, 1825-1832 (2009).

43) Rangan GK, Wang Y, Harris DC. Dietary quercetin augments activator protein-1 and does not reduce nuclear factor-kappa B in the renal cortex of rats with established chronic glomerular disease. Nephron, 90, 313-319 (2002).

44) Shoelson SE, Lee J, Goldfine AB. Inflammation and insulin resis- 
tance. J. Clin. Invest., 116, 1793-1801 (2006).

45) Kubota S, Ozawa Y, Kurihara T, Sasaki M, Yuki K, Miyake S, Noda K, Ishida S, Tsubota K. Roles of AMP-activated protein kinase in diabetes-induced retinal inflammation. Invest. Ophthalmol. Vis. Sci., 52, 9142-9148 (2011).

46) Yang Z, Kahn BB, Shi H, Xue BZ. Macrophage alphal AMP-activated protein kinase (alpha1AMPK) antagonizes fatty acid-induced inflammation through SIRT1. J. Biol. Chem., 285, 19051-19059 (2010).

47) Darville MI, Eizirik DL. Regulation by cytokines of the inducible nitric oxide synthase promoter in insulin-producing cells. Diabetologia, 41, 1101-1108 (1998).

48) Kapur S, Bédard S, Marcotte B, Côté CH, Marette A. Expression of nitric oxide synthase in skeletal muscle: a novel role for nitric oxide as a modulator of insulin action. Diabetes, 46, 1691-1700 (1997).

49) Sugita H, Fujimoto M, Yasukawa T, Shimizu N, Sugita M, Yasuhara S, Martyn JA, Kaneki M. Inducible nitric-oxide synthase and NO donor induce insulin receptor substrate-1 degradation in skeletal muscle cells. J. Biol. Chem., 280, 14203-14211 (2005). 